\title{
Establishment of Visual Monitoring Platform for Industry Expansion Report Installation Process
}

\author{
Wu Xiaomei', Wang Dan', Wang Yuting', Zhou Jinghua', Xi Dan², Shan Jia², and Wang \\ Qinghao $^{2}$ \\ ${ }^{1}$ Fuxin Power Supply Company, Liaoning Electric Power Company Limited, State Grid, China \\ ${ }^{2}$ Fushun Power Supply Company, Liaoning Electric Power Company Limited, State Grid, China
}

Keywords: Business environment, intelligence, business expansion report installation process, visual monitoring, data

\begin{abstract}
In order to further create a good business service environment and improve the service level of industry expansion and installation, the company team created a visual monitoring platform for the industry expansion and installation process by using intelligent technology. This article introduces the platform's hierarchical network format monitoring model, Discusses the creation process of the platform from model creation, platform functions to data acquisition, data release, etc., and introduces the characteristics of the intelligent technology used. Through the creation of a visual monitoring platform for the industry expansion report installation process, the company has achieved business expansion The comprehensive management and control of the packaging process and the sharing of resources within the company greatly improve the efficiency of the process, make the company more accurately serve the demand for power supply services, provide a strong support for the optimization of the company's expansion of the packaging service model, and enhance the company's overall operation Provide services with efficiency and effectiveness.
\end{abstract}

\section{Introduction}

Today, with the continuous development of the market economy, the country attaches great importance to optimizing the construction of the business environment. The general secretary pointed out that it is necessary to create a stable, fair and transparent business environment, reduce market operating costs, improve operating efficiency, and enhance international competitiveness. As the country "goes the comprehensive implementation of the "capacity and structure adjustment" policy and the continuous deepening of supply-side structural reforms, Liaoning Fuxin Power Supply Company, as a central enterprise team under this general environment, undertakes the arduous task of high-quality and reliable power supply in key national economic transformation cities. The company strives to create a good the business service environment, the original inefficient manual monitoring mode and the single mode relying only on the business system can no longer meet the sudden increase in data volume.

Fuxin Company breaks and improves the original organization and management mode of the expansion and installation services of the original industry, solidifies the concept of State Grid Corporation of "speaking with data, using data analysis, and using data to make decisions", and implements a new power supply service model relying on the value of data assets. Creating an online visual monitoring platform to control and control the power-supply process, creating an optimal service brand, and further improving work efficiency are the intelligent needs of serving the local economy, and actively serving the comprehensive transformation and upgrading of the local economy and economic and social development.

\section{The Original Problem}

The operation of the industry expansion report installation process has developed from the original mode of relying on inefficient manual to the use of marketing business application systems. 
Although it has achieved offline processing to online processing, it has not yet realized the whole process can be monitored in a real sense. It is just a single operation of each process, but we cannot view the operation status of multiple or all processes as needed, and we cannot achieve monitoring and trend analysis. Therefore, today, with full service to optimize our business environment, it is difficult to realize the digitization and intelligentization of the industry expansion and installation process, it is difficult to achieve the goal of improving quality and efficiency.

In addition, in the operation of the original industry expansion and installation process, all levels can only look at the process itself from the same perspective, and cannot monitor the process from the perspective of the level requirements. The smallest unit of the process is only divided into links, and the management and control work cannot be implemented to people and restrictions. It has achieved comprehensive management and control of business expansion and installation.

\section{Create Ideas}

Create a visual monitoring platform with a hierarchical grid model as the core, mainly relying on a new power supply service model of data asset value, based on operational data, grasp the data value of the industry expansion and installation process, and apply modern intelligent technology to the industry expansion and installation Visually monitor the execution of the entire process.

Among them, the level refers to the vertical top-to-bottom layering, that is, the three levels of the leadership decision-making layer, the management responsibility management layer, and the grass-roots staff operation layer; the grid refers to the horizontal business, and the business process is decomposed into Process-link-node grid. It is composed of vertical hierarchical and horizontal business decomposition, which together form a three-dimensional hierarchical network format monitoring model. From the "4 + 1" dimension ("scale, quality, efficiency, compliance" during the creation process "+" Collaboration "), using a variety of analysis languages, analysis databases and programming languages to realize the visualization of the monitoring platform.

\section{Creation Process}

\subsection{Create A Hierarchical Grid Monitoring Model}

Vertical business hierarchical monitoring. The hierarchical level refers to the three hierarchical levels from top to bottom, that is, the company's leadership decision-making layer, management control layer, and grass-roots employee operation layer. Expand the relationship between the business and data through business expansion the analysis and research, as well as the degree of support of the survey data for monitoring, determine the three levels of operational monitoring. These three levels are independent and connected to each other, and each level can be linked to each level of monitoring content as needed to achieve overall assurance. The goal of the smooth expansion of the business expansion and installation business and the promotion of the overall business development.

Horizontal process grid control. Grid refers to horizontally decomposing the business expansion report installation process into nodes, horizontally forming process-link-node classification, the process is dynamic, and the step-by-step completion of nodes reflects the dynamic nature of the process The horizontal process dynamically changes according to the direction of the node's completion, and a three-dimensional model of the grid format is formed between each vertical level.

\subsection{Functions of Visual Monitoring Platform}

Visualization is to change the invisible and cumbersome business process into a flow chart composed of various business links and nodes that can be displayed, time status, change trend, etc. The main functions of the visualization platform can realize the key user project process to achieve $7 * 24$ hour visualization Monitoring, regular reporting of key links, and obstruction of project collection issues; highlighting key links and collaborative links of all user project processes, and querying related process execution units, departments, positions, personnel, time, etc.; setting pre-alarms Information, find abnormal processes in a timely manner; dispatch transaction orders to 
discover the reasons for the transactions in a timely manner; notify relevant departments in time for coordination and resolution, etc.

\subsection{Data Acquisition}

There are several ways to obtain basic data for the business expansion report installation business process. The online system data comes from the sg186 system (marketing business application system) background program language acquisition, and the offline business data comes from the business department intranet program timing Reporting, WeChat information transmission, etc.

Data acquisition tools include Microsoft Excel VBA (Visual Basic for Applications) programming language, SQL (Structured Query Language) structured query language, MySQL (relational database management system), intranet mail, WeChat, etc.

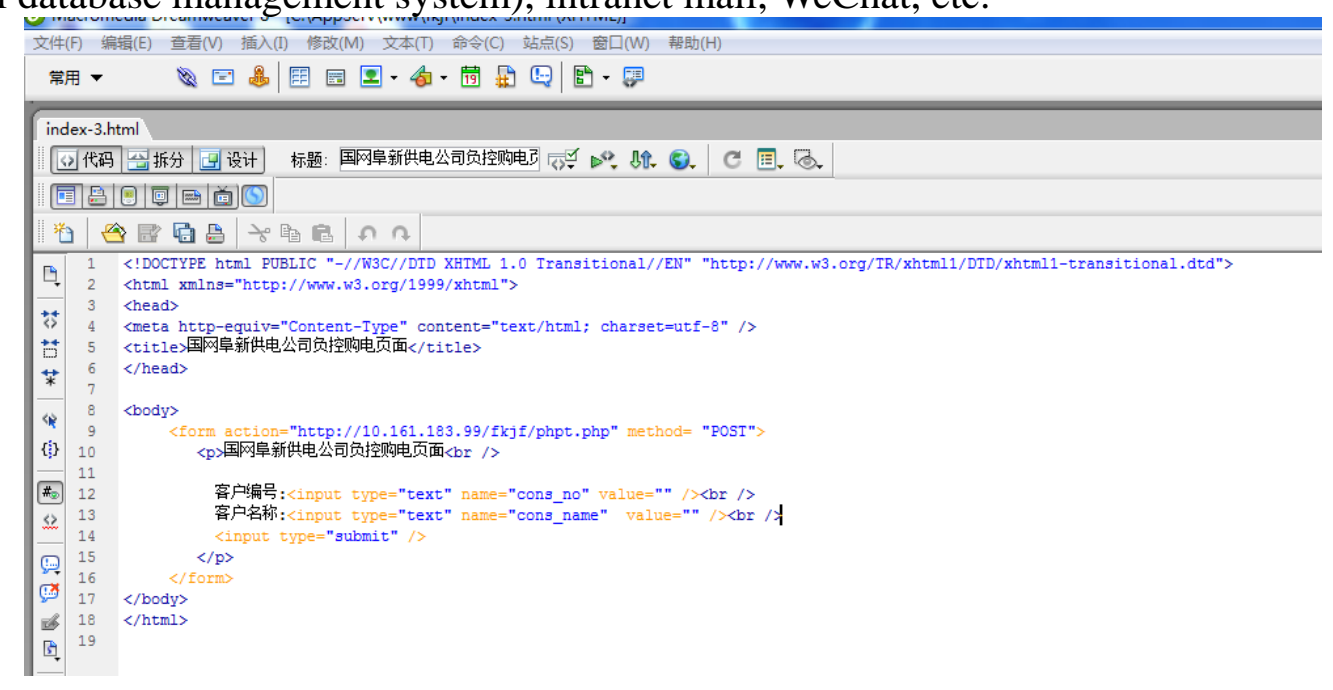

Figure 1 SQL data query language legend

\subsection{Data Release}

The platform's data publishing method is based on web development web publishing, using PHP + MySQL + Apache + Dreamweaver web development combination technology. In addition, R language is also used for statistical calculations and chart formation.

PHP, MySQL, and Dreamweaver are all software with rich functions. PHP + MySQL + Apache is used to configure and build the server environment; MySQL builds the database and data tables required for testing; and uses Dreamweaver to develop Web pages.

The data publishing process is to enter the URL in the address bar of the IE browser in the foreground to display the input page, enter the data, and successfully submit it to the background Apache server after submission. Oracle database, after successfully extracting the expected data, it is displayed normally. The $\mathrm{R}$ language is used to release the visual analysis chart.

\section{Technical Characteristics}

The main technology used is the golden combination of PHP + MySQL + Apache + Dreamweaver. Among them, PHP (Hypertext Preprocessor) is a Web programming language, MySQL is a relational database management system, Apache is a Web server, and Dreamweaver is a Web graphical programming tool. In addition, $\mathrm{R}$ language (The $\mathrm{R}$ Programming Language) is also used, which is a software for statistical calculation and statistical drawing.

Using PHP + MySQL + Apache + Dreamweaver intelligent technology, it can realize the automatic acquisition of data such as the time of the installation process and the installation information, calculate the operation time of the installation process and other information, and integrate the function into the browser to automatically calculate the timeout warning The warning message about overtime. Its advantages are: 1 . It can realize automatic calculation; 2 . The calculation time is short; 3 . It can realize the whole process of monitoring automation; 4 . The 
technical cost is relatively low.

\section{Practical Application}

The full process visual monitoring platform for industry expansion and installation is applied to the management and control of the industry expansion and installation business of power supply services in Fuxin area, as follows:

\subsection{Node Monitoring of The Process}

Completed the monitoring of the average duration of all nodes of the high-voltage new installation, high-voltage capacity expansion, and temporary electricity installation of the 14 prefectures and cities in the province in 2019, and realized the efficiency of each completed node of Fuxin Company in 2019. The time limit ranking. By participating in the industry expansion report installation evaluation seminar organized by the marketing department, the team introduced the monitoring program to the business department to discuss the feasibility of the application, which has been applied in the actual node monitoring business in 2019 and obtained the high praise. The operation interface of node monitoring is as follows.

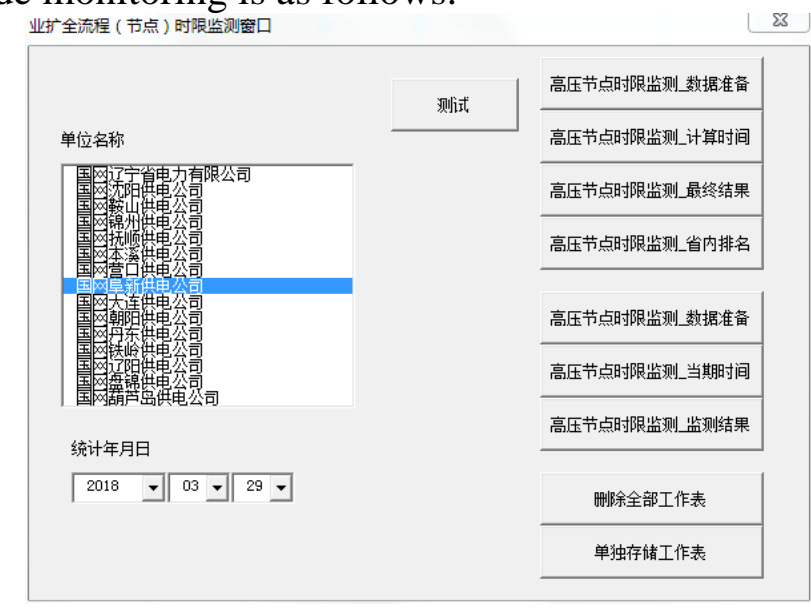

Figure 2 Node monitoring of the implementation process

\subsection{Customer Manager Progress Report Sending}

The company can not obtain the progress of key work orders in time, and the reasons that affect the progress of work orders cannot be resolved in time. Therefore, a customer manager progress reporting system is established through this platform. The customer manager is responsible for collecting external link progress and market environment information, and providing regular feedback. The system guarantees timely and accurate data feedback mechanism, realizes the control of feedback progress information, and solves the problems of high-frequency information acquisition and information transmission of many key work orders.

\section{Conclusion}

The team found new platforms on HowNet, State Intellectual Property Office and other platforms, and found no similar platforms. By creating this platform, it can enable companies to more accurately serve the needs of power supply services, and provide optimization for the company's industry expansion and installation service model. Strong support. Realized the sharing of resources within the enterprise, so that the monitoring rate of the industry expansion report installation process reached more than 98\%, and the industry expansion report installation management gradually moved closer to intelligence, improving the enterprise's intelligence level; Comprehensive management of the industry expansion report installation process, the connection time of $10 \mathrm{kV}$ high-voltage customers decreased by $22.48 \%$ year-on-year, greatly improving the efficiency of the process and providing services for improving the company's overall operating 
efficiency and benefits. The efficiency and benefits of external services have been improved, and good economic and social benefits have been achieved, with broad application prospects and good promotion value.

\section{References}

[1] He Zhengyou. Distribution network analysis and application [m]. Beijing: Science Press, 2014, 6 (2): 54-60.

[2] Wei Zheming, Zhang Shuyu. User Power Supply Reliability Management Manual [s]. Beijing: China Water Resources and Hydropower Press, 2016, 3 (3): 79 (5): 137.

[3] Wang Jiye. Smart grid big data [m] Beijing: China Electric Power Press, 2017, 2 (2): 80-113, (3): 255-289.

[4] Wang Yimin. User Power Supply Reliability Management Workbook (Second Edition) [s]. Beijing: China Electric Power Press, 2009, 4 (2): 34-42, (4): 73-82.

[5] (British) Meyer-Schonberg, (British) Cooke. The era of big data [m] Zhejiang People's Publishing House, 2013, (5) 374-383. 